\section{Fernand Braudel e a geo-história das civilizações}

\section{Fernand Braudel and the geo-history of civilizations}

\section{Guilherme Ribeiro}

Professor adjunto de geografia do Instituto de Ciências da Sociedade e Desenvolvimento Regional/Universidade Federal Fluminense.

Rua José do Patrocínio, 71

28015-030 - Campos dos Goytacazes - RJ - Brasil geofilos@ig.com.br

Recebido para publicação em maio de 2010

Aprovado para publicação em dezembro de 2010.
RIBEIRO, Guilherme. Fernand Braudel e a geo-história das civilizações. História, Ciências, Saúde-Manguinhos, Rio de Janeiro, v.18, n.1, jan.-mar. 2011 p.67-83.

\section{Resumo}

Discute a importância da geografia para o estudo das civilizações no livro Grammaire des civilisations, do historiador francês Fernand Braudel, bem como o papel epistemológico do conceito de geo-história em seu pensamento. Parte da hipótese de que a geografia foi crucial para a apreensão da história de longa duração.

Palavras-chave: geografia; geo-história; Fernand Braudel (1902-1985); civilizações; longa duração.

\section{Abstract}

The article discusses the valuable role of geography in the study of civilizations entitled Grammaire des civilisations (A history of civilizations), by French historian Fernand Braudel. It also focuses on the epistemological role of the concept of geo-history in Braudel's thought. The article's underlying assumption is that geography has been crucial to comprehending history over large spans of time.

Keywords: geography; geo-history; Fernand Braudel (1902-1985); civilizations; long time spans. 
$\mathrm{N}_{\mathrm{p}}^{\mathrm{o}}$ o período entre La Méditerranée et le monde méditerranéen à l'époque de Philippe II ${ }^{1}$, publicado em 1949 e Grammaire des civilisations ${ }^{2}$, que surgiu em 1963, Braudel investe boa parte de suas forças tentando esboçar um projeto de reorganização epistêmica das ciências do homem à luz da longa duração, o que, desnecessário esclarecer, confere à história lugar central nessa empreitada. É o que revelam, particularmente, os artigos "Pour une économie historique" (1950), "Histoire et sciences sociales" (1958), "Histoire et sociologie" (1958-1960) e "Unité et diversité des sciences de l'homme" (1960). ${ }^{3}$ Neles, observamos Braudel dar sequência à interdisciplinaridade dos primeiros Annales - porém visando dotá-la de contornos mais precisos.

Independentemente do formato concebido, cabe destacar sua percepção precoce quanto ao fato de $\mathrm{o}$ avanço (e, de certa maneira, a sobrevivência) das pesquisas em ciências humanas estar diretamente ligado ao diálogo e à aproximação entre elas. À exceção de algumas ocasiões, não encontramos aquela ânsia de demarcar fronteiras e domínios específicos que tanto inquietara Durkheim, Bloch e Febvre. Ao contrário, Braudel estava plenamente consciente da artificialidade dos campos disciplinares e, por conseguinte, de seus procedimentos - da fragilidade, enfim, inerente às ciências do homem. Embora declarasse que a história tinha "a última palavra" (Braudel, 1996a, p.355), que apenas os historiadores sabiam lidar com o tempo (Braudel, 2005, p.35) ou que a sociologia e a história eram as duas únicas ciências que se poderiam debruçar sobre qualquer aspecto da vida social (Braudel, 2005, p.99), nem por isso ele deixou de compreender que o mundo fenomênico se restringia ou só seria explicado por uma disciplina. Daí a insistência no diagnóstico de que história e sociologia viviam em plena crise - crise da especificidade, do particularismo, do encerrarse em si. De certa forma, seus próprios avanços impediam-nas de enxergar o isolamento e a fragmentação em que se encontravam. ${ }^{4}$ Em artigos iniciados em 1941 e retomados em 1943-1944, no cárcere, ele apontava que a geografia e a história viviam a crise da descrição e da narração, respectivamente. E as articulava sob um novo conceito - géohistoire - como tentativa de superação de tal estado (Braudel, 1997, p.68-114). Em 1958 abriria o leque, professando: "Há uma crise geral das ciências do homem: estão todas esmagadas sob seus próprios progressos, ainda que seja apenas devido à acumulação dos novos conhecimentos e da necessidade de um trabalho coletivo, cuja organização inteligente falta ainda erigir..." (Braudel, 2005, p.41). Poderíamos sugerir que Braudel antecipou alguns elementos da perturbação mais ampla da década de 1960, que culminaria com a emergência da pósmodernidade? Um deles está bem evidente: a crítica ao fracionamento disciplinar. O outro é mais latente, embora só possa ser reconhecido quando se observa sua obra como um todo: a rejeição à ortodoxia da razão moderna.

Braudel era ambicioso. E já dera provas disso em 1949, quando o manejo de tópicos como economia, política, sociedade, geografia e cultura, distribuídos conforme a diversidade espacial do Mediterrâneo, fez do seu livro uma ave rara. Tal ambição expressava visão de longo alcance sobre a capacidade analítica das ciências sociais, que, em sua opinião, não deveriam negligenciar nem se confinar ao particular, ao singular, à explicação unilateral, mas sim trabalhar visando ao total, ao global, à construção de modelos, ao levantamento de hipóteses. Por essas razões impunham-se os câmbios disciplinares. Não que elas precisassem negar a si mesmas, mas sim abrir-se às demais. Repetindo o espírito e as palavras de Vidal de 
la Blache, dirá que elas estão "contaminadas umas pelas outras" (Braudel, 2005, p.54). ${ }^{5}$ Nas entrelinhas, parecia dizer que as ciências do homem são a verdadeira filosofia de nosso tempo. A elas cabe questionar a vida do homem em sociedade, seus hábitos culturais, crenças religiosas, visões de mundo, relações com a natureza, disputas com o 'outro'. As respostas, todavia, não estão em teorias herméticas, conceitos fixos, dialéticas ou afins, mas única e exclusivamente na diversidade histórica e material da experiência vivida. Fernand Braudel parte de coisas simples, banais até: comer, beber, vestir, trocar coisas, deslocar-se. Inicialmente, não há altas elucubrações em torno disso. A complexidade da sociedade é derivada da própria metamorfose vivida pelos homens, sobretudo após o século XVI: explorações continentais, viagens ultramarinas, expansão global do comércio, intercâmbios culturais, casas de câmbio, letras de crédito, formação de impérios, organização de Estados nacionais, controle territorial, migrações em massa, espraiamento da industrialização, progressos técnicos... Por isso ele insiste tanto em observar, descrever, relatar. São recursos metodológicos que fazem valer o predomínio da manifestação empírica (desigual no tempo e no espaço) como traço nuclear das ciências do homem.

A atração pela geografia vem dessa moldura geral. A herança francesa afirmava a variedade regional do território e o estabelecimento dos gêneros de vida de acordo com as condições naturais, técnicas e sociais de cada grupo e lugar. Ao estender tal reflexão às civilizações, eis um mundo feito heterogêneo. Embora as estruturas manifestem tendência a padronizar determinados costumes e práticas, elas também precisam adaptar-se às cores locais. A geografia enquadra-se na escrita histórica braudeliana tanto por sua proeminência física inexorável, quanto por suas coerções estruturais à vida humana. A realidade circundante é geográfica: a agricultura depende (até hoje) dos humores do clima; a economia tem na circulação uma de suas variáveis mais essenciais; as políticas nacionais e imperiais se assentavam com a autoridade sobre os territórios; as civilizações - ele definiu (Braudel, 1996c) - são espaços. Uma estrutura é algo que não se desmancha, ainda que se transforme. Ela acompanha e define os contornos mais amplos da história das sociedades. A geografia é uma estrutura; ela desafia a história. E acaso a concepção braudeliana não grifará as vitórias, perdas e adaptações do homem perante o espaço? Nesse sentido, ele a utiliza para captar a realidade viva e concreta do movimento da história, as estratégias civilizacionais de sobrevivência e a longa duração.

Em 1958, o autor explicitava parte de suas intenções com a geografia:

O exemplo mais acessível parece ainda o da coerção geográfica. Durante séculos, o homem é prisioneiro de climas, de vegetações, de populações animais, de culturas, de um equilíbrio lentamente construído do qual não pode desviar-se sem o risco de pôr tudo novamente em jogo. Vede o lugar da transumância na vida montanhesa; a permanência de certos setores da vida marítima enraizados em certos pontos privilegiados das articulações litorâneas; a durável implantação das cidades; a persistência das rotas e dos tráficos; a fixidez surpreendente do quadro geográfico das civilizações (Braudel, 2005, p.50).

São essas injunções, essa presença constante dos aspectos geográficos interagindo com sociedades e civilizações que intrigam o mestre francês e o impelem a considerar vigorosamente o papel desses aspectos no processo histórico. Não que as coerções impeçam; elas desaceleram a história. Fazem lembrar que o ritmo do homem não é igual ao da 
natureza; que o homem não está 'sozinho' no mundo; que a história não se dá a seu belprazer. De qualquer maneira, depende-se do espaço, seja do quadro natural inicial, seja do meio já produzido e modificado humanamente. Decerto que, implícitas ou explícitas, nele há vantagens; certa predileção braudeliana em ver a história como um obstáculo. Entretanto, no livro publicado em 1963, assinala: "Assim, as respostas do homem não cessam, ao mesmo tempo, de libertá-lo do meio que o cerca e de sujeitá-lo às soluções que ele imaginou. Ele sai de um determinismo para recair em outro" (Braudel, 2004, p.33). Eis que estamos, de alguma maneira, diante do legado vidaliano. As perguntas de ambos são iguais: como as civilizações tiram proveito ou não de seus ambientes? Como explicar a diversidade de desafios colocados pelo meio e que lição extrair das respostas dadas pelas civilizações? Em que medida essa trama se inscreve na história global das civilizações?

Isso mostra também que Braudel considerava a geografia tanto em seu lado físico quanto em suas feições humanas e que sua visão de determinismo, coerentemente casada com sua acepção de história, é bem menos simples do que se imagina (Ribeiro, 2008). Revela ainda que, embora enfatize as injunções, não deixa de lado as possibilidades. Fato é que, na longa duração, o homem se apossou do espaço, tornou-o habitável e materializou o mundo como cenário de suas operações mais corriqueiras. É essa dialética envolvendo determinismo e conquista espacial que nos coloca em oposição a juízos como os de que o tempo longo "colonizou" (Santos, 2002, p.266) ${ }^{6}$ ou "encerrou" (Ozouf-Marignier, Robic, 2000, p.268) a geografia, bem como a afirmações de que "a geo-história é um operador do tempo imóvel" (Dosse, 2004, p.127).

Que, em Braudel, a geografia esteja subordinada à história, assim como, aliás, a sociologia, a antropologia, a economia e as demais ciências; que haja críticas sobre sua interpretação geográfica, tudo isso sem dúvida é indiscutível. Advogaríamos, todavia, que o historiador francês levou o conhecimento geográfico às últimas consequências: ao passado profundo e sua relação com o presente; à escala mundial, quando a disciplina tradicionalmente se vincula às escalas regional e nacional; à análise econômica, terreno em que ela só avançou efetivamente a partir da década de 1950. Ainda que o próprio Braudel tenha afirmado a associação entre geografia e tempo longo, não significa que haja ortodoxia, a não ser que se discorde a priori da relevância heurística da longa duração ou se considere que nela não há movimento. Suas ponderações sobre o papel das cidades como polo a atrair pessoas, mercadorias e fluxos financeiros, ou quando privilegia a dinâmica da circulação no exame da modernidade, por exemplo, nada têm de imobilismo. Igualmente, a interpretação espacial do capitalismo e seu conteúdo denso de geopolítica (no sentido lato de estratégias econômicas, políticas e sociais para a otimização do uso do espaço) situam a geografia como ferramenta essencial de um dos maiores projetos intelectuais idealizados pelas modernas ciências do homem.

A questão tal como vimos apresentando pretende destacar os papéis da geografia na escrita histórica braudeliana. Nessa trilha, nos deparamos com a posição de Daix (1999, p.278), para quem nosso investigado teria "renunciado a seu neologismo 'geo-história". Em sua opinião, isso se deve ao fato de que, na segunda edição de La Méditerranée, em 1966, Braudel teria conseguido livrar-se do determinismo, noção incongruente com a concepção de história que ele tentava afirmar. Como provas, Daix aponta a retirada da 
conclusão "Géohistoire et déterminisme", algumas mudanças na montagem dos capítulos, a posição acadêmica, a maturidade intelectual adquirida e, sem dúvida, a herança geográfica apropriada e superada pela história. Ocupando quatro páginas e entremeada por citações do livro em tela, nos é permitido recortar a argumentação literal do autor que, entretanto, não por isso deixa de expô-la de forma minimamente coerente:

Conclusão parcial ["Géohistoire et déterminisme"] que mais uma vez deixava transparecer certo embaraço face à geografia. Conclusão na qual se multiplicavam os exemplos para justificar comparações ousadas entre experiências afastadas no tempo, mas apesar de tudo conclusão então inovadora... Mas se Braudel tratava então, e com razão, de expulsar este excesso de determinismo pela porta da história, a geografia e mesmo a sua 'geo-história' traziam-no de volta pela janela. Ei-lo então acuado a recorrer a nuanças que debilitam seu projeto e no fim das contas o diminuem, chegando acaso a pôr em risco esta emancipação da história face à geografia ... [Não obstante, o] profundo trabalho empreendido por Braudel na segunda edição a respeito das 'crises políticas urbanas' mostra como ele se saiu desse debate, que já não pertence à sua 'nova história'. Sua decisão foi tomada em favor da importância das escolhas, das tentativas dos homens face às possibilidades da geografia. ... Em vista do próprio movimento de conjunto do livro, foi a história que tomou a frente da herança da geografia por demais estática que Braudel recebeu na época de sua formação. ... As modificações operadas na segunda parte, "Destinos coletivos e movimentos de conjunto", não são da mesma ordem que as da primeira, pois Braudel já liberara esta parte da ganga geográfica e da história factual ao mesmo tempo (Daix, 1999, p.276-279; grifos nossos).

A admiração pela pesquisa de Daix - como fonte de consulta plena de informações e detalhes importantes, por abranger os três grandes livros e cobrir a história intelectual da França durante o século XX - não nos interdita o exercício da crítica. Assim, poder-se-iam identificar quatro itens de sua fala a ser questionados: (1) a géohistoire não é sinônimo de determinismo; uma breve leitura de La Méditerranée é suficiente para perceber que a dimensão geográfica que emana da análise social, econômica e política está longe de ser monopolizada por uma abordagem determinista; (2) Braudel não rejeita de todo o determinismo e a 'ganga geográfica', pois ao homem as possibilidades não são ilimitadas - postura em total sintonia com sua concepção estrutural de história; (3) sugerir uma 'nova história', ao comparar as duas edições do livro mencionado, contraria a trajetória intelectual de seu autor, em que inovações e aperfeiçoamentos andam ao lado de profunda coerência teóricometodológica; (4) seria absolutamente correto sustentar que a geografia era estática no período de formação de Bloch e Febvre; este não é, entretanto, o caso de Braudel, cujo curso de história apresentava passividade contrastante com o ensino de geografia de então. Ele mesmo ressalta o papel de Demangeon na introdução de 1966 (Braudel, 2002), e o próprio Daix o havia feito com eloquência logo no início de seu trabalho!? Passemos, porém, a palavra ao próprio Braudel, cuja definição de géohistoire em 1949, mais do que nossos argumentos, mostra precisamente o oposto do desfecho de Daix:

pretendemos designar algo diferente do que está implicado na geopolítica, algo mais histórico e ao mesmo tempo mais amplo, que não seja simplesmente a aplicação, à situação presente e futura dos Estados, de uma história espacial esquematizada e, o mais das vezes, previamente direcionada num determinado sentido... . Obrigar a geografia a repensar, com seus 
métodos, seu espírito, as realidades passadas e, por isto mesmo, aquilo que poderíamos denominar os devires da história (Braudel, 1949, p.295; grifos nossos). ${ }^{8}$

A géohistoire é, portanto e antes de tudo, algo aberto e plural (não é assim todo o pensamento do historiador francês?). Tomando o conceito de geopolitik como base de crítica para engendrá-la - o que não significa, de modo algum, descartar a importância de seu conteúdo estratégico -, o sucessor dos primeiros Annales pretende, pelo menos, três coisas: (1) dotar o neologismo de densidade histórica, capacitando-o a explorar as dimensões da longa duração ("algo mais histórico", "as realidades passadas"); (2) fugir de qualquer tipo de dogmatismo (político, estatal ou determinista-mecanicista) e esquematismo (a introdução geográfica à história, por exemplo), liberando seu uso aos mais diversos campos da vida social (sem estar "previamente direcionado num determinado sentido"); (3) associar o passado mais longínquo ao presente e ao futuro ("os devires da história").

Se levarmos ao pé da letra o que Daix $(1999$, p.278) realmente afirmou - "Compreendese assim que Braudel tenha renunciado a seu neologismo 'geo-história'" -, é até possível conceder-lhe alguma razão, já que o uso da expressão praticamente desaparece após 1949. É mister, todavia, destacar que a démarche braudeliana - a ênfase na observação, descrição e interpretação de dados e fenômenos empíricos, o emprego despreocupado e desapegado junto aos conceitos, a preferência ao concreto e ao visível - é parte integrante de um processo geral de estruturação epistemológica das ciências do homem, cuja edificação se fez pela desconfiança dos modelos iluministas de conhecimento. Este é ponto essencial: por mais que Braudel tenha elaborado uma concepção de história - e isso comporta, pelo menos, o esforço em definir um campo de delimitação e uma metodologia para a consecução do ofício do historiador com interpretação original do processo histórico -, nem por isso podemos dizer que ele se pôs a trabalhar rigorosamente à base de conceitos e categorias analíticas. ${ }^{9}$

Além disso, e sobretudo, não há abandono da geo-história simplesmente porque, no limite, isso significaria renunciar à própria ideia de história tal como Braudel a imaginava e praticava. Mais do que um recurso, um 'operador' ou um diálogo com a geografia, a géohistoire é, praticamente, a própria história braudeliana. Se em 1949 ela surgia como neologismo - na verdade, mais correto seria mencionar o início da década de 1940, quando da preparação do artigo "Géohistoire: la société, l'espace, le temps" (Braudel, 1997) -, na década de 1960 já estava plenamente integrada à escrita histórica de seu criador, cuja obra é globalmente atravessada por raciocínios espaciais, um traço constituinte de sua visão de mundo. E se a segunda edição de La Méditerranée acusa alguma transformação em torno desse ponto, ela não deixa de estar relacionada aos desenvolvimentos conceituais ocorridos no interior do pensamento geográfico. Sugerindo alternativa à posição de Daix, o que queremos dizer é que a geo-história foi 'substituída' pelo espaço. Ligada à Escola Francesa de Geografia, a gênese daquele conceito tinha como propósito maior a incorporação do meio à história, fosse por intermédio das lições de Vidal de la Blache sobre os gêneros de vida, fosse pela diversidade empírica aportada pelas monografias regionais. Como já mencionamos, Braudel (assim como Bloch e Febvre) não se apropriaria das contribuições urbanas, econômicas e geopolíticas engendradas por aquela corrente; tais temas acabariam por fazer parte do legado geográfico alemão e de seu tripé espaço-economia-sociedade. Ele 
as articulou durante toda sua obra, inclinando-se ora para uma, ora para outra. Assim, $L a$ part du milieu (primeiro volume de La Méditerranée, 1949), Les structures du quotidien (1967), L'identité de la France (1986) e Grammaire des civilisations (1987) aproximam-se da tradição francesa, ao passo que Destins collectifs e mouvements d'ensemble (segundo volume de La Méditerranée), Les jeux d'èchange e Le temps du monde (volumes 2 e 3 de Civilisation matérielle; Braudel, 1979a, 1979b) inspiram-se na tradição alemã. ${ }^{10}$

Tudo indica que o termo espaço tem a função de unificar esses dois aspectos - que Braudel, mesmo quando censurou a geopolítica, jamais considerou opostos. Por fim, será que poderíamos aventar a possibilidade de a substituição do conceito de géohistoire pelo vocábulo espaço não estar ligada a uma tentativa de ir além da junção de duas disciplinas, mas sim de captar as dimensões espaçotemporais da vida social?

\section{A geografia como linguagem na gramática das civilizações}

Nesse sentido, o recurso da comparação é iluminador. Embora as atenções estejam voltadas a $L a$ part du milieu quando se quer associar Braudel à geografia, em Grammaire encontramos um Braudel mais à vontade no desenvolvimento de seus raciocínios geohistóricos. Olhando apenas para a primeira parte de La Méditerranée, alguém poderá dizer que se trata de reflexão cuja tendência aponta para o rural e para as consequências dos condicionamentos naturais na história. Certamente essa não é uma visão correta para a seção 1 e tampouco para a 2, em que os elementos geográficos urbanos e econômicos entram em cena. Em Grammaire, todavia, constata-se uma geografia cujo potencial foi explorado sob vários ângulos, da descrição física dos países e continentes ao exame de seus sítios e posições ${ }^{11}$, passando pela conexão entre cidade e campo até chegar à valorização do espaço (as mudanças na relação campo/cidade, o declínio das economias urbanas, a ascensão das economias nacionais, os processos de formação territorial e afins). A relação homem/ natureza permanece, mas a mudança de escala em comparação a La Méditerranée provoca revisão analítica segundo a qual as questões geográficas são intensificadas e, mesmo, sofisticadas. Para além do determinismo-possibilismo, a discussão mais abrangente e densa pode ser assim resumida: o espaço é coordenada histórica fundamental da vida social. é o que ele desenvolverá soberbamente em Civilisation matérielle, uma história total dos espaços sob o prisma da longa duração.

A escala mundial liberou a plenitude do potencial geográfico. É uma geografia menos física e mais móvel. Braudel demonstra que a história das sociedades é inseparável do espaço - e isso fica mais evidente na escala em tela, em que se nota ser o espaço, para além de seu aspecto físico (área a ser ocupada, por exemplo), elemento constituinte de tais histórias e não algo 'externo'. Nas estreitas dimensões do Japão ou da Europa, ou no caso oposto do Brasil e da América Latina, as civilizações envolvidas têm um desafio comum: elas devem 'domesticá-lo', 'domá-lo'; diminuir, senão relativizar, seu estado inóspito, selvagem. Para tanto, entram em jogo os transportes, as comunicações, o povoamento, os atrativos econômicos, os conflitos territoriais. Não se trata, contudo, de decisões e planejamentos meramente racionais stricto sensu. A lógica que domina o jogo espacial diz respeito às escolhas, às respostas dadas pelas civilizações e isso inclui a cultura, as mentalidades, as 
características que lhes são intrínsecas. ${ }^{12}$ Não obstante, como lidamos com uma história mundial, um de seus traços principais é a transferência, o intercâmbio, configurando um quadro de coexistência, 'colagem', mistura. ${ }^{13}$ Quer seja a Europa, por si só diversa (o cruzamento das tradições mediterrânea e nórdica, por exemplo), a intersecção Europa/ África/Ásia ou a imposição da civilização ibérica junto ao Novo Mundo, há que levar em consideração que, a cada etapa de aprofundamento rumo à história mundial, seguia-se uma geografia igualmente mundial. Como conceber a geografia de países como Brasil, México ou Índia sem a ingerência de portugueses, espanhóis e britânicos? Afinal, paralelamente à posse da escrita, que impôs a dominação cultural, ocorria a dominação espacial através do aparato cartográfico, militar e técnico desenvolvido pelos europeus. Como alcançar o contraste entre a fragmentação territorial da África e a delimitação mais precisa do mapa político da América do Sul, senão pela contenda entre vários impérios europeus por aquele continente e sua partilha, sobretudo por Portugal e Espanha? Como justificar a densidade da malha de transportes e da urbanização brasileiras no litoral, senão através dos interesses firmados pelas potências europeias em construir uma economia agroexportadora por excelência?

É por essas e outras razões que a geo-história braudeliana se amplia, sem deixar rastro de dúvidas sobre a indissociabilidade de espaço e tempo, sobre o fato de que não existe história fora dos ambientes geográficos. Verificar o embate homem versus meio e mapeá-lo de acordo com as civilizações permitem a constatação de que não há tempo único, cronologia lisa, indiferente, vazia, mas sim uma geografia do tempo histórico - um mosaico de tempos históricos em que cada civilização, mesmo em contato com outra, guarda ritmo particular. E parte desse ritmo diz respeito à maneira como as civilizações se relacionam com seus espaços específicos. O espaço atravessa, explode a sequência rígida, fechada e padronizada da cronologia, desviando-a e pulverizando-a em ritmos quase tão distintos quanto a diversidade do próprio espaço. Ele pertence ao plano das múltiplas singularidades formadas pela associação de homem e meio em cada região. Focalizar a escala mundial, todavia, significa reunir tais singularidades não num só ritmo, mas numa única e total história. Significa retirá-las do particular e conduzi-las ao global, aproximando homens, ambientes, desafios e soluções.

A sedução de Grammaire sobre um geógrafo está no fato de termos, pela primeira vez, a oportunidade de ver uma história geral acompanhada de uma geografia geral. Não uma história geral 'das partes', mas sim do mundo; uma história tecida pelo capitalismo e pela modernidade. Não uma história geral seguida de introdução geográfica geral, mas sim uma exposição clara e coerente do espaço em sua condição de ser um dado e um produto histórico, elemento a priori imposto ao homem e consequência histórica. O tempo, seja o evento, a conjuntura ou a estrutura, é uma abstração. O espaço é espesso; sui generis é a realidade orgânica e artificial - dado da natureza e constructo humano. Ele determina que seja empírica a percepção da mudança e da permanência. Por isso Braudel insiste nos componentes orgânicos e biológicos, pois a história dos homens é, até o século XVIII, uma tentativa mundial de domar ambientes que insistiam em permanecer selvagens. Boa dose dessa argumentação está sintetizada no polêmico vocábulo determinismo: o peso da natureza sobre as sociedades, peso só contornável (e não totalmente, decerto) quando 
situado na longa duração. Daí o papel cabal dos conceitos de civilização e civilização material, visto que se encaixam perfeitamente na apreensão da história longa e, de imediato, promovem a ligação com o espaço. Essa proximidade confunde até mesmo o próprio Braudel, que afirma ser a mais longa das histórias ora a civilização, ora a relação do homem com a terra. ${ }^{14} \mathrm{~A}$ história, no entanto, faz progressos e o espaço se transforma. Atento a isso, ele retrata as paisagens modernas, a sociedade urbana, as cidades. A vida passa a girar em torno delas, que concentram o dinheiro; são o palco da vida política; ditam a moda, os costumes e o padrão de sociabilidade. Junto com o aprofundamento das relações capitalistas, sua proliferação parece tornar mais explícitas as desigualdades espaciais. Indubitavelmente, um capítulo à parte do pensamento braudeliano foi dedicado às cidades (ver Fourquet, 1991), merecendo destaque seja pela nitidez literária de suas descrições, ou pelo exame de sua posição nuclear na história do mundo moderno. ${ }^{15}$

Situado entre as edições de La Méditerranée de 1949 e 1966, Grammaire é peça importante porque demonstra bem a transição braudeliana rumo à espacialização definitiva da história - cujo primor de arte seria Le temps du monde..$^{16} \mathrm{~A}$ seguir, interpretaremos algumas passagens ilustrativas desse movimento, mais precisamente o resgate histórico dos vínculos entre homem e meio até chegar à valorização total do espaço.

No subtítulo "As civilizações são espaços", Braudel proclama que, independentemente de seu tamanho, elas

\begin{abstract}
sempre podem localizar-se num mapa. Uma parte essencial de sua realidade depende das restrições ou das vantagens de sua localização geográfica. Naturalmente, essa localização foi adaptada pelo homem desde há séculos, ou mesmo, muitas vezes, desde há milênios. Não há paisagem que não traga a marca desse trabalho contínuo, aperfeiçoado ao longo de gerações - em suma, capitalizado. Graças a esse labor, o homem transformou a si mesmo por esse 'poderoso trabalho de si sobre si' de que fala Michelet ou, se preferir, por essa 'produção do homem pelo homem' como diz Marx. Falar de civilização é falar de espaços, terras, relevos, climas, vegetações, espécies animais, vantagens dadas ou adquiridas ... . Obviamente, o meio ao mesmo tempo natural e fabricado pelo homem não aprisiona tudo de antemão num determinismo estreito. O meio não explica tudo, embora represente um grande papel, na forma de vantagens dadas ou adquiridas (Braudel, 2004, p.31-32; grifos nossos).
\end{abstract}

Logo no início do livro, eis o mestre francês reunindo, implícita ou explicitamente, heranças dispersas e distintas: os primeiros Annales e o conceito de civilização; Vidal de la Blache e o aporte da cartografia, da análise de posição e da paisagem; a historicização dos fenômenos com Michelet e Marx. Diríamos que a citação anterior encarna a síntese de um projeto: enriquecida pela ciência geográfica, a história deixa de ver os homens separados de seus ambientes; amparada no processo histórico, a geografia não corre o risco de precipitar-se na ladeira no determinismo. Através das civilizações, a geo-história (eis o projeto) alcança todas as esferas da vida social. Seja a política, a economia, a cultura ou as mentalidades, nenhuma delas escapa a um determinado contexto espaçotemporal. Esta é premissa básica, código de entrada para acessar o pensamento braudeliano: a história ocorre em profunda agregação com o meio, que tanto constrange quanto promove a ação humana e funciona ora como desvantagem, ora como vantagem. Porém, observando esse vaivém na escala da longa duração, notar-se-ão algumas metamorfoses. De um lado, a 
dinâmica ininterrupta da natureza joga contra o homem; de outro, a técnica, o trabalho e a ciência jogam contra a natureza. O meio vai assumindo novas feições, torna-se cada vez mais solícito às demandas sociais:

Assim, a geografia, à primeira vista, testemunha sobre a diversidade, e não sobre a unidade desses países [Índia e China] de múltiplas fisionomias. Talvez, então, ela nos extravie, estando, por isso, o problema mal colocado? Não é o meio geográfico, em si muito diversificado, que cria a unidade do Sudeste Asiático, mas sim uma civilização material bastante monótona, que se impõe em quase toda parte e que se acrescenta aos elementos geográficos, físicos e humanos. Essa civilização é por demais antiga, está por demais enraizada em idades remotas, é "o produto de um número muito grande de processos de psicologia individual e coletiva para que seja lícito fazê-la derivar apenas do meio físico local" (P. Gourou). Ela existe em si mesma, força mais que semi-independente, determinante por sua vez (Braudel, 2004, p.160).

Nem sempre, porém, é este o caso. Embora Braudel tenha praticado a história em escala global, nem por isso incorreu em explicações padronizantes. É o que revela sua exposição acerca da África negra, na qual afirma que, embora o "determinismo geográfico não comande tudo por si só[,] ... a geografia prevalece sobre a história. Os contextos geográficos, embora não sejam os únicos a contar, são os mais significativos" (Braudel, 2004, p.128129). Aqui ele se apresenta de maneira mais clássica em relação à geografia, associando-a às características naturais e evocando os gêneros de vida, o que lhe permite recorrer ao caráter tradicional das sociedades da África negra e grifar o fato de que elas ainda não conseguiram desenvolver as condições necessárias para contornar as influências do meio. Às vezes, contudo, até os resultados da engenharia são insuficientes para tanto. O Islã seria exemplo de lugar em que, apesar das construções hidráulicas e das culturas em solo seco, o peso do deserto distribui irregularmente a população, afetando a vida como um todo (p.76-77).

As cidades, no entanto, implodiriam a vida camponesa, a escala local e a relação com a natureza. Nesse caso, a força motriz é menos a civilização material - que domina amplamente a atividade humana até por volta do século XVIII (Braudel, 1985, p.43-44), porém restrita à subsistência e ao comércio de curta distância - do que a economia de mercado e suas redes de pessoas e mercadorias a ligar, pouco a pouco, o território nacional até extrapolálo de vez. Com o capitalismo, a cidade assume o papel de ser a expressão mais fiel do mesmo. Nela, faz-se a política, a economia, o espaço. O meio vai sendo parcialmente recoberto graças ao trabalho, à materialidade das construções e ao estabelecimento de massa humana cada vez maior, emprestando ao cotidiano o movimento, a velocidade e a expansão típicos da dinâmica capitalista. Em decorrência disso, Braudel constata que as sociedades não são influenciadas apenas pelos ambientes naturais, mas que, no transcorrer do processo histórico de complexidade de seus mecanismos, são afetadas também pelos ambientes produzidos.

As ligações de cidade e campo fornecem perfeita ilustração do tema:

O desenvolvimento das cidades acarretava, por si só, a brusca deterioração de sua paisagem humana e material. Todos os observadores se inquietam com isso, de Balzac a Victor Hugo. Miséria, mendicância, assaltos a mão armada, delinquência, crianças errantes, epidemias, criminalidade, tudo é agravado pelo rápido amontoamento de trabalha- 
dores na indizível promiscuidade das paredes estreitas. Porque os provincianos não param de chegar. Em 1847, Michelet ainda observa que o camponês "admira tudo na cidade, tudo deseja, ali ficará se puder... Depois que se saiu do campo, não se volta mais a ele" ... Parece que a sociedade urbana foi, então, particularmente transtornada por uma indústria que a atinge, a atrai, sem ser capaz de soerguê-la, nem sequer de fazê-la viver. Talvez essa miséria citadina não seja pior, em última análise, que a dos campos de então. Nas cidades, porém, aos olhos de todos, exibe-se o espetáculo alarmante de uma população de trabalhadores vítimas da indústria que, quando lhes fornece trabalho, pouco se preocupa com suas condições de vida (Braudel, 2004, p.358; grifos do original).

Impunha-se uma nova organização do espaço e, com ela, a reorganização interna da sociedade. Expandiam-se os limites dos lugares conhecidos; aumentava-se a mobilidade da população; diminuía-se sensivelmente o tempo das viagens; teciam-se redes sociais, físicas e financeiras. Lendo Grammaire hoje (e a obra de seu autor como um todo), um geógrafo tende a dizer que Braudel reconstitui, peça por peça, as territorialidades formativas da modernidade: da fixação camponesa à fluidez citadina; da lentidão da vida rural à conturbação urbana; do raio curto da civilização material à escala intercontinental. Para tanto, vários fatores entram em cena: a técnica (construção de rotas e meios de transporte), a política (formação dos Estados nacionais e controle do território), a economia (o mercado e o capitalismo articulando espaços), a sociedade (as migrações rumo às cidades), a cultura (adesão ao estilo urbano e consumista). Averiguando uma dessas territorialidades, emergirá a imbricação das diferentes camadas da vida social. Uma mudança em uma delas provoca reação em cadeia, afetando por conseguinte as demais.

Ao abranger espaço, economia e sociedade, aprendemos que:

as corporações de ofício trabalham ao mesmo tempo para o mercado local e para o comércio distante. É fora de dúvida que a economia urbana só pôde prosperar como fez porque extrapolou largamente a economia local. No século XV, a cidade de Lübeck, a mais importante da vasta associação comercial que veio a chamar-se Hansa, conjunto de cidades comerciais disseminadas desde o Báltico até o Reno, mantém relações com a totalidade do mundo então conhecido. O mesmo se pode dizer de Veneza, Gênova, Florença ou Barcelona. Nesses centros privilegiados, um primeiro capitalismo triunfa como 'comércio distante'. É o começo do reinado dos comerciantes-empresários, que fornecem matérias-primas e trabalho e asseguram a venda dos produtos industriais, enquanto os mestres de ofícios tornam-se cada vez mais assalariados, assim como seus 'oficiais' nesse Verlagsystem .... Os comerciantes são os grandes personagens do popolo grasso. A arraiamiúda, o povo 'magro', se revoltará com frequência, mas em vão. Em Gand, por exemplo, ou em Florença, onde a violenta revolução dos ciompi eclode em 1381..." (Braudel, 2004, p.298; grifos do original).

É isso que entendemos por valorização total do espaço: não apenas os contornos físicos dos fenômenos econômicos, políticos, culturais e sociais dispostos num mapa refém do plano cartesiano, mas o exame das mudanças espaciais situadas historicamente e dos papéis desempenhados pelo espaço na composição dessas mudanças. E, se no campo historiográfico a longa duração pode ser interpretada (erroneamente, a nosso ver) por alguns como uma espécie de inércia ou estabilidade (Guriêvitch, 2003), no terreno geográfico é justamente o contrário. Uma 'geograficidade' viva, pintada com intensidade, prazerosa de ver e ler - a 
variedade de ambientes naturais, as características das civilizações, os campos e as cidades, a extensão da economia de mercado, a abrangência global do capitalismo, a distribuição da população, as reformas urbanas, as fronteiras dos Estados, o jogo de escalas MediterrâneoFrança-mundo... Em virtude disso, talvez devamos reposicionar os termos da questão: se é verdade que Braudel tem uma dívida intelectual com a geografia, cabe a ela agora reconhecer que sua obra a levou aos mais variados graus de análise no tempo e no espaço. Isento das querelas internas que obstruíram o desenvolvimento de seu potencial heurístico (as dicotomias geral/regional, idiográfico/nomotética, físico/humana), ele pôde conduzir o saber geográfico com toda a liberdade possível e desejável. Não houve qualquer crítica relevante de fundo a ser levada em conta - e tampouco esboço de diálogo efetivo por parte dos geógrafos...

Suas observações sobre a América Latina são representativas da intensidade geográfica de sua escrita histórica; logo, o espaço é fator crucial. Na prática, ele interfere no cotidiano, na economia e na política, ou seja, no processo histórico como um todo. Na teoria, mostra temporalidades diferentes, que a cronologia é incapaz de apreender. Daí a função da geografia: ela materializa a história, ela 'ajusta' o ritmo do tempo. Desse modo, as demarcações históricas só têm razão de ser quando 'geografizadas'. Há sentido falar em Antiguidade referindo as civilizações indiana e chinesa? Haveria coerência em aplicar a expressão Idade Média ao continente americano? É bem verdade que a segunda metade do século XX, que entrará para a história por conta do espraiamento e da intensidade da globalização, viu a emergência de fenômenos que sugerem vivermos em tempo, sociedade e aldeia globais. De toda maneira, russos, norte-americanos, brasileiros, sérvios, chineses, congoleses e australianos, reunidos todos num cronológico século XXI, não estão na mesma 'etapa' histórica e tampouco suas experiências espaçotemporais são iguais quando falamos em modernidade, por exemplo. Além disso, é mister grifar que a globalização vem acompanhada de processos de fragmentação nas mais variadas escalas. Para uma compreensão menos difusa dos nossos dias, uma das lições a reter da obra braudeliana é a de que a unificação do mundo pelo capitalismo não é sinônimo de padronização cultural, social ou histórica. A geografia das civilizações, edificada na longa duração, mostra isso perfeitamente.

Uma das imagens mais vivas dessas viagens clássicas [as de Humboldt e de Saint-Hilaire]: aquela, sem dúvida, das tropas de burros, com suas rotas fixas, seus horários quase, e suas 'estações', esses ranchos onde animais, mercadorias e homens fazem alto ao entardecer para retomar o caminho no dia seguinte. Essas caravanas de burros, primeiro carreto, primeiras estradas de ferro, afirmou-se... Primeiros meios de dominar o espaço, selvagem e proliferante ainda hoje. Porque, sob os nossos olhos, se o homem não se enraíza francamente como no Ocidente, se ele deixa sua terra com demasiada facilidade, é porque o espaço superabunda pouco mais adiante. Ainda hoje, rios de rebanhos continuam a percorrer o coração do continente, como no século XVI ou no XVII, para surgir, no fim do caminho, nas feiras tradicionais de gado, como no interior do estado baiano. Há ali uma forma primitiva, pouco dispendiosa de exploração, um capitalismo barato, tanto assim que o espaço é dado de graça, ou quase. Nada mais natural que os homens - perdidos, submersos no espaço-, as cidades - sobretudo elas, situadas a meses e meses de distância das metrópoles europeias ou das capitais coloniais - e as províncias - algumas mais vastas que a Itália ou a França-acabem se governando um pouco à sua maneira. Sobretudo ontem, na falta de coisa melhor e porque, 
antes de mais nada, é preciso viver. Nas duas Américas, a 'democracia americana', com seu self-government, é filha, em parte, do espaço. Desse espaço que amortece tudo e conserva tudo - pelo menos, enquanto não for vencido (Braudel, 2004, p.388-389; grifos nossos, com exceção de 'ranchos' e 'self-government').

Continente da imensidão a tragar a vagarosidade dos homens e das coisas nos exórdios da modernidade - natureza abundante, mas nem sempre hospitaleira -, desprovido das técnicas de deslocamento e das redes de circulação que já envolviam a Europa, eis alguns desafios que a história, a seu turno, dramatizaria sem qualquer pudor. Feito laboratório da Europa, o Novo Mundo inculto e pagão formar-se-ia civilização através da mistura de raças e das explorações coloniais e de 'dependência'. As consequências seriam, em essência, extremas desigualdades sociais e espaciais - traços que não passam despercebidos por nosso investigado, que critica a violência de uma economia feita exportadora de matérias-primas, o arcaísmo do setor primário e a insuficiência alimentar da América do Sul. Salientando disparidades como a pujança de Brasília, os subúrbios ricos da cidade do México, os arranhacéus de São Paulo, o isolamento 'medieval' de lugares como Minas Velhas e Ubatuba, a desterritorialização (o vocábulo é nosso) dos camponeses em Buenos Aires e o "colonialismo interno" (Braudel, 2004, p.385-408), Braudel retoma a constatação que Vidal de la Blache fizera há mais de cinquenta anos: a má utilização do espaço. Coincidência ou não, ambos também abordaram a mesma área geográfica: as Américas. Coincidência ou não, ambos passavam pelo mesmo tema: a divisão internacional do trabalho. A crítica de Braudel desvenda a sensibilidade espacial inscrita em sua análise histórica:

Os capitalistas estrangeiros (ou melhor, as grandes empresas internacionais), aliados aos grandes proprietários e aos políticos locais, dirigiram a produção para as matérias-primas exportáveis, obrigando assim as regiões produtoras a concentrar todos os seus esforços, homens e recursos numa única atividade, exclusiva, em detrimento de todas as outras. $\mathrm{O}$ desenvolvimento daí resultante teria podido, com o tempo, dar seus frutos para o conjunto do país, se a frequente mudança da demanda não aniquilasse regularmente tais investimentos. Era preciso, então, concentrar bruscamente os esforços em outro setor da produção e daí, como muita frequência, em outra região. A variedade dos climas e a superabundância do espaço permitiram à América do Sul suportar essas extraordinárias mudanças de direção que foram, de fato, no plano nacional, um desperdício inaudito de espaço e de homens: elas impediram, em toda parte, o estabelecimento de estruturas econômicas duradouras, estáveis, sãs, bem como o enraizamento de uma classe camponesa (Braudel, 2004, p.398; grifos do original).

\section{Considerações finais}

Preparado como parte de um manual para os estudantes do último ano dos liceus franceses, o conceito de civilização, caro para os Annales, foi aprofundado por Braudel manejando-o geograficamente no plano da longa duração (Dagorn, 2003). Com esse livro, fez-se um casamento completo: um Braudel maduro no que tange à escrita histórica põe em prática suas formulações epistemológicas.

Nesse sentido, a geografia é crucial para apreender as realidades de longa duração. Se o conceito de géohistoire não foi mais utilizado por Braudel desde La Méditerranée, isso não 
significa que ele deixou de lado seu conteúdo. Muito pelo contrário; o raciocínio braudeliano é todo geo-histórico, posto que incorporar o meio e o espaço significava estratégia epistemológica a fim de operar uma história estrutural. Se as civilizações são espaços e fenômenos de longa duração, a geografia é parte crucial dessa gramática.

\section{NOTAS}

${ }^{1}$ Publicado em português como O Mediterrâneo e mundo mediterrâneo na época de Felipe II (Lisboa, Dom Quixote, 1983).

${ }^{2}$ Publicado como Le monde actuel em 1963 (Paris, Belin); reeditado em 1987 com o título Grammaire des civilizations (Braudel, 1987). Para a edição brasileira, ver Braudel, 2004.

${ }^{3}$ Publicados em Écrits sur l'histoire (Braudel, 1969a, 1969b,1969c,1969d).

${ }^{4}$ Eis uma lição de interdisciplinaridade que passou quase totalmente em branco: as ciências sociais "fragmentaram o real, por espírito sistemático mas também por necessidade: qual de nós não se especializou, de certa maneira de nascença, por capacidade ou por tendência para penetrar este ou aquele setor do conhecimento e não outro? ... O ideal impossível seria apresentar tudo num único plano e num só movimento. A prática recomendável é, ao dividir, conservar na mente uma visão globalizadora: ela surgirá forçosamente na explicação, tenderá a recriar a unidade, aconselhará a não acreditar numa falsa simplicidade da sociedade ..." (Braudel, 1996a, p.408-409).

${ }^{5}$ Manifestava-se Vidal em 1899 (!), defendendo a dimensão geográfica a ser incorporada pelas outras ciências e, ao mesmo tempo, sua unidade: "Assim, as ciências da terra, e mesmo certas ciências do homem, acusam uma tendência a se desenvolver num sentido mais geográfico. Esta tendência surge das próprias necessidades de sua evolução. Ao avançar, elas têm reencontrado a geografia em seu caminho. $\mathrm{Na}$ realidade, tudo isso é apenas expressão da unidade fundamental que as religa. A relação entre elas não consiste apenas em simples transferências de resultados, mas no fato de que estão mutuamente impregnadas em seus métodos" (Vidal de La Blache, 1899, p.106-107; grifos do original). Meio século depois, Braudel resguardava a ampliação da história e, simultaneamente, a aproximação com as demais ciências: "O historiador quis-se atento a 'todas' as ciências do homem. Eis o que dá ao nosso mister estranhas fronteiras e estranhas curiosidades. Além disso, não imaginemos, entre o historiador e o observador das ciências sociais, as barreiras e diferenças de ontem. Todas as ciências do homem, inclusive a história, estão contaminadas umas pelas outras. Falam a mesma linguagem ou podem falá-la" (Braudel, 2005, p.41; grifos do original). Só o desconhecimento da obra de ambos assimilaria as passagens acima como mero fruto do acaso. São notórias as afinidades entre o pensamento vidaliano e a escrita histórica braudeliana. A saber: comparação, visão de conjunto, unidade científica, métodos comuns; diversidade da experiência humana, relevância social da natureza, sedução pela civilização material.

${ }^{6}$ Não sabemos se Santos apurou com clareza a proposta de Braudel: primeiro, não se trata de um par (tempo curto/tempo longo), mas sim de uma trindade (o evento, a conjuntura e a estrutura); segundo, o geógrafo brasileiro relaciona o tempo curto às conjunturas - o que não é o caso, já que é o acontecimento que se liga ao tempo curto; terceiro, parece haver exagero quanto ao impacto das temporalidades braudelianas nas ciências humanas e, sobretudo, nas naturais e exatas. Finalmente, ao pretender substituir as noções de tempo curto/tempo longo pelo binômio tempo rápido/tempo lento, não se trata de avanço teórico nem, tampouco, de ganho de objetividade (como queria o autor). O lado ímpar (para não dizer irônico) de tudo isso é que Santos (2002, p.107) vê La Méditerranée como "modelo definitivo" de uma geografia retrospectiva.

7 "Digamos, para sermos diretos, que a geografia - para quem tinha, como ele, o espírito aberto e ao contrário de uma história que se limitava a reiterar e remoer velhas histórias - era na época a ciência de ponta. Graças ao reinado de Vidal de la Blache, ela desfruta desde o fim do século anterior de um imenso prestígio, não apenas nacional, mas internacional. E o merece plenamente, pois não seria exagero afirmar que desempenha então, na passagem da história para as ciências humanas nascentes, o papel de fermento intelectual, de modelo de estruturação que seria desempenhado no início da segunda metade do século XX pela linguística e a antropologia. Hoje, que temos uma visão retrospectiva, podemos afirmar que ela foi, no desenrolar da formação de nosso jovem historiador, a extraordinária oportunidade que permitiu a sua vida sair dos limites da 'história historicizante'. A geografia lhe oferece, com efeito, muito antes que a palavra virasse moda, o 'modelo' de uma ciência capaz de confrontar a atividade dos homens com fenômenos envolvendo transcursos diferentes do tempo" (Daix, 1999, p.62). 


\begin{abstract}
${ }^{8}$ Nesta e nas demais citações de textos em outros idiomas, a tradução é livre.
${ }^{9}$ Sua acepção de sociedade como nada mais que o 'conjunto dos conjuntos' mostra um pouco dessa postura. Ao tentar justificá-la, ele argumenta: “o interesse de uma definição é fornecer uma problemática prévia, regras para uma primeira observação. Se ela facilita essa observação, no seu início e no seu desenvolvimento, se, em seguida, há uma classificação aceitável dos fatos, depois uma superação lógica, a definição é util e justifica-se. Ora, não será a expressão conjunto dos conjuntos útil para recordar que toda realidade social, observada em si, se situa num conjunto superior; que, feixe de variáveis, chama, implica outros feixes de variáveis ainda mais amplos?" (Braudel, 1996a, p.408; grifos do original). Ou seja, para Braudel o conceito não é captura, mas sim liberdade de pensamento para movimentar-se diante do empírico. Nesse sentido, a explanação em seu último livro é reveladora: "cabia-me a obrigação de dizer, sem mais, aquilo que eu via, e aquilo que, ao ver, eu acreditava compreender. ... O todo observável forma uma única massa, que é preciso tornar clara, pacientemente, acendendo e reacendendo a lanterna. Sem muito hesitar, abandonei-me então à observação, ao comentário direto, sem me preocupar em demasia em estar ou não seguindo a linha direta de nossas categorias científicas - categorias que aliás criamos artificialmente" (Braudel, 1989, p.17; grifos nossos).
\end{abstract}

${ }^{10}$ Reproduzindo suas aparições literais conforme os índices, temos, em Grammaire, "As civilizações são espaços", "Os espaços", "Espaço e liberdades", "O espaço europeu se define: séculos V-XIII" e "Espaço, natureza e sociedade: o testemunho de uma literatura"; em Les structures du quotidien, "Conquista de espaços"; em Les jeux d'échange, "As firmas tem seu espaço" e "Espaços urbanos"; em Le temps du monde, "As divisões do espaço e do tempo na Europa" (título do capítulo I), "Primeira regra: um espaço que varia lentamente", "Terceira regra (continuação): o esquema espacial da economia-mundo", "Os espaços do Norte: a sorte de Bruges", "Os espaços do Norte: a sorte de Hansa", "Uma gama de espaços", "Espaços e mercados provinciais", "A superabundância de espaço" e "Um espaço marítimo longamente salvaguardado"; e, por fim, em L'identité de la France, "Espaço e história" (título do v.1), "Espaço e história: últimas palavras" e "O espaço crescente das cidades". A palavra não aparece em nenhuma das duas edições de La Méditerranée.

${ }^{11}$ Esse é um traço constante do livro em tela, lembrando um pouco as antigas introduções geográficas à história. Porém, é recurso metodológico que não guarda nenhuma ingenuidade: "Primeiro, a geografia. A Coreia foi vítima de sua singular posição estratégica, entre o arquipélago japonês, a Manchúria, a Sibéria e a China. É ela um exemplo dos perigos que ameaçam os pequenos Estados na vizinhança dos grandes, que, hoje como ontem, se acreditam no direito de fazer com eles o que bem entendem. Vasta península $\left(220 \mathrm{mil} \mathrm{km}^{2}\right)$ orientada, em linhas gerais, do norte para o sul, a Coreia só está separada da Manchúria pelos estreitos vales do Yalu e do Tumen, que correm paralelamente a essas altas Montanhas Brancas cujo anteparo, de fato, protegeu ou mesmo criou a independência da Coreia. Do paralelo 43 ao 34, a Coreia é um dique de 800 a 900 quilômetros, à primeira vista muito semelhante à península italiana" (Braudel, 2004, p.258). Avançando um pouco mais, ele explicaria com transparência a inelutabilidade, mas não o determinismo, da dimensão geográfica: "Ver o Extremo Oriente, situar esse imenso teatro é compreender, mais que parcialmente, seu destino e suas estranhas civilizações. Para esta primeira tomada de contato, os viajantes, os jornalistas e os geógrafos são os melhores guias. Desde que não expliquem tudo de maneira autoritária a partir de um determinismo geográfico absoluto, que não existe mais na Ásia que na Europa ou em qualquer país longamente trabalhado pela história e pelo esforço paciente dos homens" (p.159).

12 "cada civilização está ligada a um espaço com limites mais ou menos estáveis; donde, para cada uma delas, uma geografia particular, a sua, que implica uma série de possibilidades, de determinadas injunções (algumas quase permanentes) que nunca são as mesmas de uma civilização para outra. O resultado? Uma superfície variegada do mundo onde os mapas indicam, à vontade, zonas de casas de madeira, de taipa, de bambu e de papel, de tijolo ou de pedra; zonas de fibras têxteis diversas: lã, algodão, seda; zonas de grandes culturas alimentares à base de arroz, milho, trigo... Os desafios variam, e não menos as respostas" (Braudel, 2004, p.33; grifos do original).

13 "De fato, esses casos clássicos [o florescimento das civilizações chinesa ao longo do rio Amarelo, da egípcia no Nilo, da grega no Mediterrâneo] revelam sobretudo o primado da circulação. Civilização alguma vive sem movimento próprio; cada qual se enriquece com as trocas, com os choques acarretados pelas vizinhanças frutuosas. Assim, o Islã é impensável sem o movimento de suas caravanas através de seus vastos 'mares sem água', os desertos e as estepes de seu espaço, impensável sem suas navegações no Mediterrâneo e, pelo oceano Índico, até a península malaia ou a China" (Braudel, 2004, p.32).

${ }^{14}$ Em 1963, apontava: "Essas viagens através das resistências, das aquiescências, das permanências, das lentas deformações das civilizações, permitem formular uma última definição, aquela que restitui às 
civilizações sua fisionomia particular, única: elas são continuidades, intermináveis continuidades históricas. A civilização é, assim, a mais longa das longas histórias" (Braudel, 2004, p.53). Entretanto, em 1950, constatava que "ainda mais lenta que a história das civilizações, quase imóvel, uma história dos homens em suas relações estreitas com a terra que os suporta e os alimenta; é um diálogo que não cessa de repetirse, que se repete para durar, que pode mudar e muda na superfície, mas prossegue tenaz como se estivesse fora do alcance e da mordedura do tempo" (Braudel, 2005, p.26).

${ }^{15}$ Até onde nos foi possível conhecer, o pujante ramo da geografia urbana tem revelado um incompreensível silêncio diante das ricas direções e pistas de pesquisa abertas por Braudel. Os três tomos de Civilisation matérielle são fontes imperdíveis sobre os vínculos entre cidade e campo, o planejamento urbano, a arquitetura, a centralização econômica, a cultura e vários outros aspectos (Braudel, 1996c, p.439-510, 1996a, p.115-197, 1996b, p.75-155).

16 Para edição brasileira, ver Braudel, 1996a.

\section{REFERÊNCIAS}

BRAUDEL, Fernand.

Escritos sobre a história. 2.ed. São Paulo: Perspectiva. 2005.

BRAUDEL, Fernand.

Gramática das civilizações. 3.ed. São Paulo: Martins Fontes. 2004.

BRAUDEL, Fernand.

El Mediterráneo y el mundo mediterráneo em la época de Felipe II. México: Fondo de Cultura Económica. t.1. 2002.

BRAUDEL, Fernand.

Géohistoire: la société, l'espace, le temps. In: Ayala, Roselyne de; Braudel, Paule (Org.). Les ambitions de l'histoire. Paris: Éditions de Fallois. p.68-114. 1997.

BRAUDEL, Fernand.

Civilização material, economia e capitalismo: séculos XV-XVIII - os jogos das trocas. São Paulo: Martins Fontes. v.2. 1996a.

BRAUDEL, Fernand.

Civilização material, economia e capitalismo: séculos XV-XVIII - o tempo do mundo. São Paulo: Martins Fontes. v.3. 1996b.

BRAUDEL, Fernand.

Civilização material, economia e capitalismo: séculos XV-XVIII - as estruturas do cotidiano. São Paulo: Martins Fontes. v.1. 1996c.

BRAUDEL, Fernand.

A identidade da França: o espaço e a história. São Paulo: Globo. v.1. 1989.

BRAUDEL, Fernand.

Grammaire des civilisations. Paris: ArthaudFlammarion. 1.ed., 1963. 1987.

BRAUDEL, Fernand.

L'identité de la France: espace et histoire. Paris: Arthaud-Flammarion. v.1. 1986.
BRAUDEL, Fernand.

La dynamique du capitalisme. Paris: Flammarion. 1985.

BRAUDEL, Fernand.

Civilisation matérielle, économie et capitalisme: les jeux de l'échange. Paris: Armand Colin. v.2. 1979 a.

BRAUDEL, Fernand.

Civilisation matérielle, économie et capitalisme: le temps du monde. Paris: Armand Colin. v.3. $1979 b$.

BRAUDEL, Fernand.

Pour une économie historique. In: Braudel, Fernand. Écrits sur l'histoire. Paris: Flammarion. p.123-133. 1969a.

BRAUDEL, Fernand.

Histoire et sciences sociales. In: Braudel,

Fernand. Écrits sur l'histoire. Paris: Flammarion. p.41-83. 1969b.

BRAUDEL, Fernand.

Histoire et sociologie. In: Braudel, Fernand.

Écrits sur l'histoire. Paris: Flammarion. p.97-122. 1969c.

BRAUDEL, Fernand.

Unité et diversité des sciences de l'homme. In: Braudel, Fernand. Écrits sur l'histoire. Paris: Flammarion. p.85-96. 1969d.

BRAUDEL, Fernand.

Civilisation matérielle, économie et capitalisme: les structures du quotidien. Paris: Armand Colin. v.1. 1967.

BRAUDEL, Fernand.

La Méditerranée et le monde méditerranéen à l'époque de Philippe II. Paris: Armand Colin. 1949.

DAGORN, René-Éric.

Fernand Braudel et la 'Grammaire des 
civilisations' (1963). In: Lévy, Jacques; Lussault, Michel (Org.). Dictionnaire de la géographie et de l'espace des sociétés. Paris: Belin. Disponível em: http://www.espacestemps.net/document 639.html. Acesso em: 22 jan. 2006. 2003.

\section{DAIX, Pierre.}

Fernand Braudel: uma biografia. Rio de Janeiro: Record. 1.ed. francesa, 1995. 1999.

DOSSE, François.

O recurso geográfico dos historiadores. In:

Dosse, François. História e ciências sociais.

Bauru: EdUsc, p.115-148. 1.ed. francesa, 1998. 2004.

FOURQUET, François.

Cidades e economias-mundo segundo Fernand Braudel. Espaço \& Debates, São Paulo, n.33, ano 11, p.53-62. 1.ed. francesa, 1988. 1991.

GURIÊVITCH, Aaron.

A sintese histórica e a Escola dos Anais. São Paulo: Perspectiva. 1.ed. francesa, 1991. 2003.
OZOUF-MARIGNIER, Marie-Vic; ROBIC, Marie-Claire.

Un tableau à vif...: la réception du Tableau de la géographie de la France de Paul Vidal de la Blache. In: Robic, Marie-Claire (Dir.). Le Tableau de la géographie de la France de Paul Vidal de la Blache: dans le labyrinthe des formes. Paris: Éditions du CTHS. p.251-270. 2000.

RIBEIRO, Guilherme.

Espaço, tempo e epistemologia no século XX: a geografia na obra de Fernand Braudel. Tese (Doutorado em Geografia) - Instituto de Geociências, Universidade Federal Fluminense, Niterói. 2008.

SANTOS, Milton.

A natureza do espaço: técnica e tempo - razão e emoção. São Paulo: EdUsp. 2002.

VIDAL DE LA BLACHE, Paul.

Leçon d'ouverture du cours de Géographie. Annales de Géographie, Paris, v.3, n.38. p.97-109. 1899. 